\title{
Clinical characteristics and outcomes of acute community acquired pneumonia in children at a reference public hospital in Pernambuco State, Brazil (2010- 2011)
}

Rita de Cássia Coelho Moraes de Brito 1

Talitha Coelho Moraes Guerra 2

Luciana de Holanda Lima Dornelas Câmara 3

Juliana Dias Pereira Gomes de Mattos 4

Maria Julia Gonçalves de Mello 5

Jaílson de Barros Correia 6

Norma Lucena Silva 7

Giselia Alves Pontes da Silva 8

1,5 Instituto de Medicina Integral Professor Fernando Figueira. Rua dos Coelhos, 300. Boa Vista. Recife, PE, Brasil. CEP: 50.070-550. E-mail: moraesdebrito@gmail.com 2,3,4,6 Departamento de Medicina Tropical. Universidade de Pernambuco. Recife, PE, Brasil.

7 Centro de Pesquisas Aggeu Magalhães. Fundação Oswaldo Cruz. Recife, PE, Brasil.

8 Departamento de Pediatria. Universidade Federal de Pernambuco. Recife, PE, Brasil.

\begin{abstract}
Objectives: to describe the clinical characteristics and outcomes of acute community acquired pneumonia in children at a reference public hospital in Pernambuco State, Brazil (2010-2011)

Methods: pneumonia case series of 80 children aged 28 days to 14 years old at Hospital da Restauração in Pernambuco, Brazil, from 2010 to 2011. Information was noted from medical files, and two comparison groups were created according to the severity of the disease, considering the presence of pleural effusion. Fisher or Mann-Whitney tests were used for comparative analyses.

Results: severe pneumonia with pleural effusion was more frequent in children under five years of age $(p=0,025)$, and was associated with longer period of fever $(19 \times 15$ days) and coughing (17 $x 13$ days), when compared to non-complicated pneumonia cases. Six children $(7,5 \%, 6 / 80)$ died, $50 \%$ before the fourth day of hospitalization $(p=0,001)$. All deaths were from the pleural effusion group in children from the countryside $(p=0,026)$.

Conclusions: the severity of pneumonia in children attended at this hospital is related to younger children, and those transferred from the health units in the countryside, so, early diagnosis and medical intervention are limited by infrastructure and available resources for the health.
\end{abstract}

Key words Pneumonia, Pleural effusion, Epidemiological profile, Child 


\section{Introduction}

Community acquired pneumonia (CAP) is an acute inflammatory disease of the pulmonary parenchyma of infectious nature that affects individuals outside the hospital environment or appears in 48 hours after hospital admission.1,2 Brazil occupies the $15^{\text {th }}$ position among the other fourteen countries which are responsible for $74 \%$ of the disease episodes in children under five years old. ${ }^{2}$ The incidence of pneumonia among children under the age of five in developing countries is five times higher than in developed countries. ${ }^{3}$ According to the World Health Organization (WHO) data, pneumonia is responsible for $21 \%$ of children's deaths in Africa and Asia, 19\% in the Middle East and 12\% in America and Europe, becoming higher in regions that present inefficient health systems. 3,4 Of all these cases, $7-13 \%$ are serious and require hospitalization. $4 \quad 6.3$ million children died before the age of five in 2013, almost $52 \%$ (3.257 million) died of infectious diseases, being the main causes, such as diarrhea, malaria and pneumonia, however the latter killed most children. 5

In Brazil, according to the data from Departamento de Informática do Sistema Único de Saúde (Datasus) (Information Technology Department of the Unified Health System), in the period between 2008-2012, pneumonia caused 12.722 deaths in children younger than 14 years of age. 6 There are no data of pneumonia incidence in this age range and from different Brazilian geographic regions, however, 461 thousand children were hospitalized in public hospitals with the disease in 2012, and 35.380 were in Pernambuco State. 6

WHO identifies the main risk factors for severe forms of pneumonia such as age, low birth weight, malnutrition, children was not breastfed and having more than seven members in the same household, exposure to HIV, outdated vaccine calendar and low maternal schooling. ${ }^{7-9}$ However, other factors may interfere with clinical presentation of CAPas the virulence of the pathogen and the immune response of each individual.10-12 The main symptoms of pneumonia in children are fever, cough and tachypnea, ${ }^{2-5}$ but symptoms such as otalgia, 13 abdominal pain and chest pain may also be present. ${ }^{14}$ The increased intensity of respiratory difficulty is known as a predictor of severe pneumonia. ${ }^{13}$

The recognition of clinical characteristics in associated emergency care for a possible evolution of pneumonia to a pleural effusion, allows medical interventions that may positively interfere in the outcome of the patient. 16 However, this study aims to describe and compare the clinical characteristics and outcomes in cases of acute community acquired pneumonia in children assisted at a public hospital in the Northeast region of Brazil. In addition, a proposal of a flowchart for care and management of suspected cases of acute community pneumonia in children will be used in health units.

\section{Methods}

A retrospective study as case series with an internal comparison group, including patients between the ages of 28 days and 14 years old, admitted with a diagnosed hypothesis of pneumonia at Hospital da Restauração (HR) in the city of Recife, the capital of Pernambuco in the period of May, 2010 to May, 2011. HR is the largest public health network unit for emergency services and traumas managed by the Secretary of Health in the State of Pernambuco. The pediatric emergency unit offers clinical care and provides high complexity services for the sick from anywhere in the State.

From the analysis of the admission book at the emergency unit, the patients' medical files presented a diagnosed hypothesis of pneumonia and lor abdominal pain as undefined etiology, a common symptom in children with pneumonia 10 were preselected. At admission, the hypothesis of pneumonia was performed based on clinical complaints of fever and $\backslash$ or anorexia and $\backslash$ or asthenia and $\backslash$ or coughing and $\backslash$ or signs of respiratory distress, which was confirmed by the presence of radiological changes (opacity and/or a display of air bronchogram and pleural effusion, characterized by opaque hemithorax with a contralateral deviation of the mediastinal structures) (Figure 1).

The socio-demographic data (age, gender and origin), prior history (anemia, malnutrition, abdominal pain and asthma), clinical information of current disease (duration of coughing and fever), physical exam (wheezing, tachypnea and signs of respiratory failure), complications (empyema, efisema and pneumothorax) and treatments performed, all these information were obtained from medical files and registered in a specifically prepared form for this research.

The signs of severity were confirmed by the presence of the following: nostril flaring (NF), subcostal screening (SCS), peripheral oxygen saturation $\left(\mathrm{SpO}_{2}\right)<94 \%$, cyanosis and tachypnea. The latter was evaluated according to the respiration rate (RR) and age range: $\mathrm{RR}>60$ respiration movement per minute (rmpm) in $<2$ months; $R R>50 \mathrm{rmpm}$ at 2 12 months; RR $>40 \mathrm{rmpm}$ at $12-59$ months and $\mathrm{RR}>30 \mathrm{rmpm}$ in $>60$ months, these are according to 
the Diretriz Brasileira de Pneumonia (Brazilian Guideline recommendation in pneumonia). ${ }^{2}$

Data relating to the treatment, as a therapeutic scheme (penicillin and oxacillin + Ceftriaxone association) and the antibiotic change scheme, oxygen therapy, ventilatory support with the use of Venturi mask or Assisted Mechanical Ventilation (AMV) and thoracentesis for thoracic drainage were equally extracted from the medical file. There was a therapeutic failure on the registration of changing the antibiotic andlor the occurrence of one of the following complications: pneumothorax, bronchopleural fistula, persistent and/or recurrent empyema and pneumatocele.

The cases were stratified in two groups, according to the severity of the disease based on clinical and radiological criteria recommended by the Diretrizes Brasileiras de Pneumonia2 (Brazilian Guidelines for pneumonia): group I or PNM $\backslash D P$ (complicated pneumonia with pleural effusion) and group II or PNM (non-complicated pneumonia without pleural effusion).

The distribution of frequency (absolute and percentage) of demographic characteristics and hospitals between groups (group I and II) were compared by Chi-square test or Fisher bi-caudal (categorical variables) and Mann-Whitney test (continuous variable). The maximum error adopted for all statistical tests was $\alpha=5 \%(p<0.05)$. The analysis was performed in EpiInfo version 3.5.1

This study was approved by the Ethics Committee at Hospital da Restauração (HR), CAAE0029.0.102.000-11.

\section{Results}

A total of 1316 children were admitted to the pediatric ward at HR in the period of this study, 293 medical files were pre-selected, but five were not found. After the analysis of 288 medical files, 80 met the inclusion criteria of this study, which was a confirmed diagnose of pneumonia based on the clinical and radiological findings. Figure 1 shows a flowchart on selected case studied.

Of the 80 cases analyzed, most of the children were up to four years old $(72.5 \%)$, which around $1 / 3$

Figure 1

Flowchart of the study population selection.

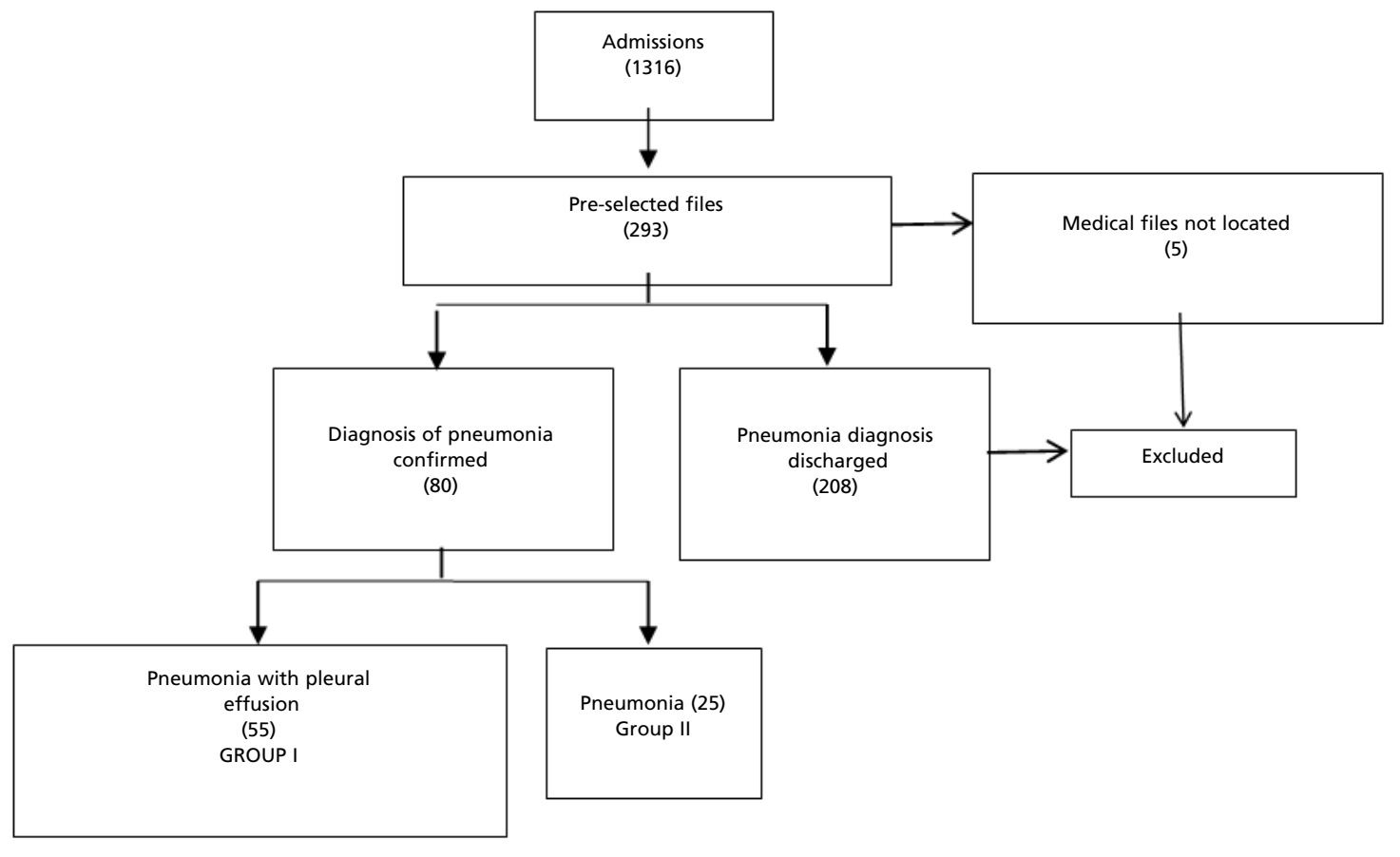


were less than 12 months old and were males (61.2\%). The proportion of the cases of severe pneumonia was higher in children below the age of four than over four ( $80 \%$ versus $56 \%, p=0.025$ ) (Table 1 ).

In group I, only three children (5.5\%) had a history of respiratory disease (asthma). As for the signs and symptoms of the current disease, most reported having fever $(88.7 \%)$ and coughing $(87.5 \%)$.

The median time of fever and coughing was higher in patients of group I (pneumonia with effusion), however no statistical significant difference $(p>0.05)$ (Table 1). Wheezing was observed in $80 \%$ of the patients with pleural effusion and in $72 \%$ of those with pneumonia and abdominal pain were frequent symptoms in this sample of both groups (Table 1).

The severity criteria mostly registered were: NF (62.5\%), tachypnea (57.5\%), SCS (46.2\%) in all the medical files mentioned cyanosis was present in six patients of group I (10.8\%) Unlike $\mathrm{SpO}_{2}<94 \%$, was registered only in $45 \%$ of the medical files. Among the signs of severity, only the screening presented a statistically significant difference comparing the PNM/DP groups $(40 \%$ and $4 \%$, respectively, with $p=0.001$ ) (Table 1). Among other morbid conditions registered in the medical files, anemia was the most frequent condition (18.7\%).

Twelve (15\%) of the 80 patients were required treatment in the intensive care unit (ICU) at the moment of admission. The closed thoracic drainage was necessary in different moments of hospitalization: at admission (52.7\%), between the $2^{\text {nd }}$ and $4^{\text {th }}$ day of hospitalization in $(30.9 \%)$, and after the 7 th day of hospitalization, $9 / 55$ (16.3\%) patients. A child remained with the drainage for 1-73 days (median 10 days). Only one patient required bilateral drainage.

In the first puncture performed after hospitalization, a cloudy pleural fluid was observed in $38 / 55$ (69\%) patients, pyohematic in $9 / 55$ (16.4\%), serous/citrine in $3 / 55$ (5.4\%), and hematic in $5 / 55$ $(9 \%)$. Of the 55 patients were drained only 9 were submitted to microbiological analysis. In these samples, Staphylococcus aureus $(\mathrm{n}=3)$ and Streptococcus pneumoniae $(\mathrm{n}=2)$ bacterias were isolated. The blood culture was performed in 24 patients, however there were no registration of the results in the medical files. As for the location of the pneumonia, the right lung was more affected than the left in both groups.

The therapeutic scheme mostly used was the association of oxacillin and ceftriaxone (53.7\%), the crystalline penicillin was chosen as the first scheme for only four patients. Of the 80 patients, 20 (25\%) presented therapeutic failure, it was necessary to change the following schemes: vancomycin and meropenem in 3 patients, vancomycin and ceftriaxone in 14, and linezolid in 3 (Table 2).

The oxygen therapy was performed in $32 \%$ of the children in group II, with a median of 4.5 days of use (3-14 days), mechanical ventilation was required in the ICU for two children, while $30.9 \%$ of the patients in group I needed oxygen therapy for a period of time that ranged from 1-79 days, with a median of 4 days, which nine patients still needed mechanical ventilation (Table 2).

As to the outcome, six children in group I died, representing $7.5 \%$ of the total of children with pneumonia, all of them came from the countryside of the state $(p=0.026)$. Among the children who died, half of the deaths occurred less than four days of hospitalization $(p=0.001)$ (Table 3$)$.

\section{Discussion}

In this present study, the median of days for fever and coughing was superior than 10 days for both groups, associated with altered respiratory frequency and wheezing. The presence of coughing and tachypnea, mainly among patients with previous history of wheezing, was not pathognomonic of pneumonia.16 However, the association of tachypnea, SCS17 and NF18 increased the chances of CAP diagnosis, especially if the patient presented coughing and fever. The presence of SCS in more than half of the cases evaluated illustrates the severity of the clinical framework in the diagnosis of children attended in the emergency research service.

The presence of abdominal pain in $20-30 \%$ of the cases is not a parameter considered in the Ministry of Health guidelines, but it can be important to identify possible cases of atypical pneumonia in children in primary care. 13.15 In a retrospective analysis between the years 2002 -2007 with children from 0-18 years old, Moore et al. ${ }^{11}$ reported that the installation of the abrupt disease (resulting in less time of having fever and coughing before admission) associated with great intensity of respiratory difficulty and are also severe pneumonia predictors in childhood.

The severity rate recommended by WHO, was not mentioned in any of the medical files at the first medical care or during the evolution of the disease. The suggestive parameters of respiratory involvement are important for the severity rating recommended by the Diretriz Brasileira de Pneumonia (Brazilian Guideline of pneumonia), including SCS, NF and $\mathrm{SpO}_{2}$, and were registered in 
Demographic characteristics of the study population according to the severity of the pneumonia at the moment of admission. Hospital da Restauração in Pernambuco, 2010-2011.

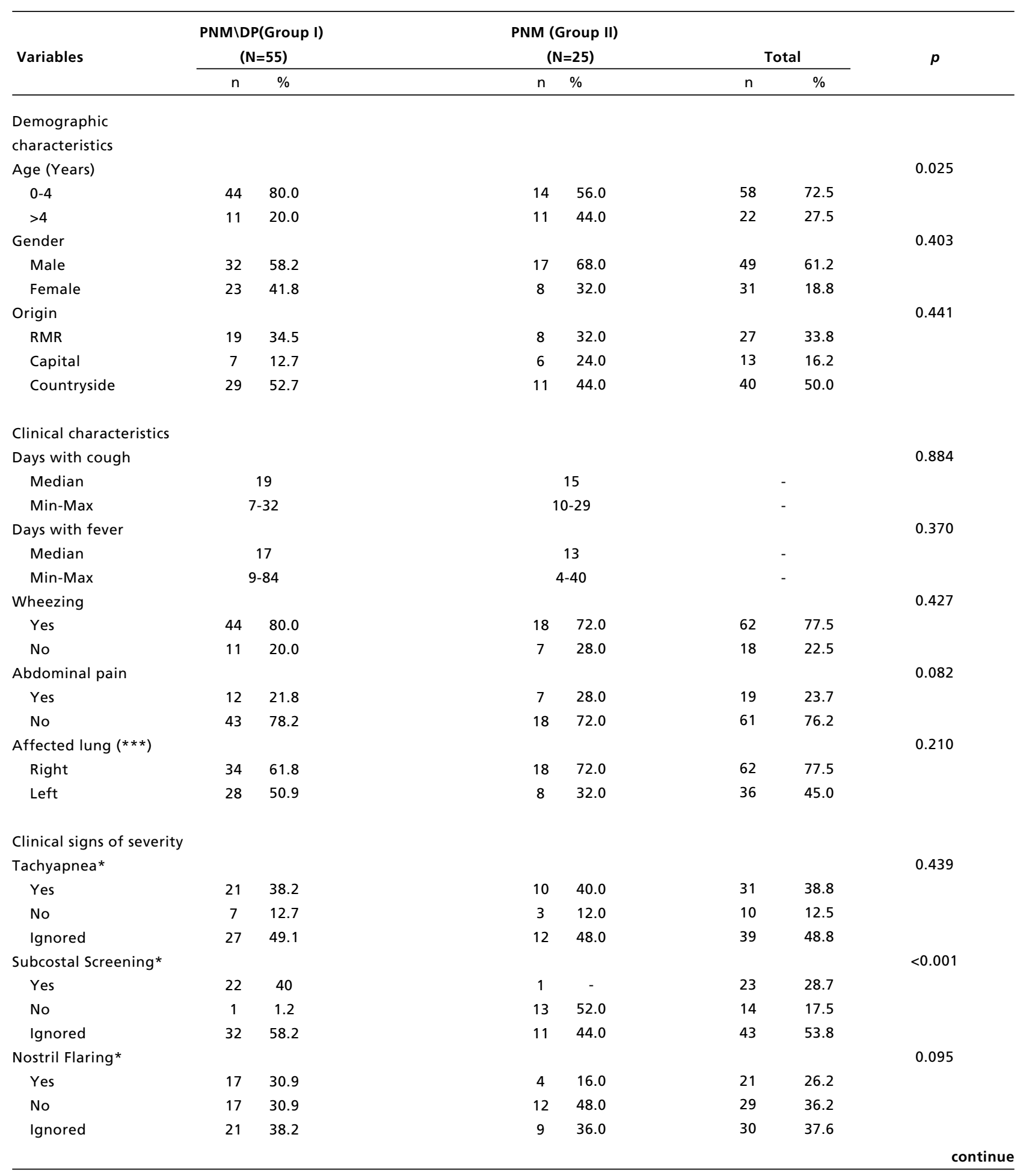

$\mathrm{PNM}=$ Pneumonia; $\mathrm{PNMDP}=$ Pneumonia with pleural effusion; RMR= Metropolitan Region of Recife; $\mathrm{O}_{2}=$ oxygen; $^{*}$ Variables with data ignored; ** Large number of medical files without this variable did not perform this statistical test; *** involvement of both lungs were observed in 7 cases of PNMDP and in 1 case of PNM. 
Demographic characteristics of the study population according to the severity of the pneumonia at the moment of admission. Hospital da Restauração in Pernambuco, 2010-2011.

\begin{tabular}{|c|c|c|c|c|c|c|c|}
\hline \multirow[t]{2}{*}{ Variables } & \multicolumn{2}{|c|}{$\begin{array}{l}\text { PNM } \backslash D P(\text { Group I) } \\
(\mathrm{N}=55)\end{array}$} & \multicolumn{2}{|c|}{$\begin{array}{c}\text { PNM (Group II) } \\
(\mathrm{N}=25)\end{array}$} & \multicolumn{2}{|c|}{ Total } & \multirow[t]{2}{*}{$p$} \\
\hline & $n$ & $\%$ & $\mathrm{n}$ & $\%$ & $\mathrm{n}$ & $\%$ & \\
\hline Cyanosis & & & & & & & 0.086 \\
\hline Yes & 6 & 10.9 & 0 & - & 6 & 7.5 & \\
\hline No & 49 & 89.1 & 25 & 100.0 & 74 & 92.5 & \\
\hline \multicolumn{8}{|c|}{ Saturation of $\mathrm{O}_{2} * *$} \\
\hline Checked & 31 & 56.4 & 4 & 16.0 & 35 & 43.8 & \\
\hline Ignored & 24 & 43.6 & 21 & 84.0 & 45 & 56.2 & \\
\hline Comorbidities & & & & & & & 0.810 \\
\hline Yes & 14 & 25.5 & 7 & 28.0 & 21 & 26.2 & \\
\hline No & 41 & 74.5 & 18 & 72.0 & 59 & 73.8 & \\
\hline
\end{tabular}

$\mathrm{PNM}=$ Pneumonia; PNMDP= Pneumonia with pleural effusion; RMR= Metropolitan Region of Recife; $\mathrm{O}_{2}=$ oxygen; $^{*}$ Variables with data ignored; ** Large number of medical files without this variable did not perform this statistical test; *** involvement of both lungs were observed in 7 cases of PNMDP and in 1 case of PNM.

\section{Table 2}

Location and days of hospitalization, procedures and treatments and children complications with pneumonia hospitalized at Hospital da Restauração in Pernambuco, from May 2010 to May 2011, according to the presence of pleural effusion.

\begin{tabular}{|c|c|c|c|c|c|c|c|}
\hline \multirow[t]{2}{*}{ Variables } & \multicolumn{2}{|c|}{$\begin{array}{l}\text { PNM } \backslash D P(G r o u p ~ I) \\
(\mathrm{N}=55)\end{array}$} & \multicolumn{2}{|c|}{$\begin{array}{c}\text { PNM (Group II) } \\
(\mathrm{N}=25)\end{array}$} & \multicolumn{2}{|c|}{ Total } & \multirow[t]{2}{*}{$p$} \\
\hline & $\mathrm{n}$ & $\%$ & $\mathrm{n}$ & $\%$ & $\mathrm{n}$ & $\%$ & \\
\hline \multicolumn{8}{|l|}{ Handling Treatment } \\
\hline Hospitalization Location & & & & & & & 0.612 \\
\hline Ward & 46 & 83.6 & 22 & 88.0 & 68 & 85.0 & \\
\hline $\mathrm{ICU}$ & 9 & 16.4 & 3 & 12.0 & 12 & 15.0 & \\
\hline Hospitalization duration $>14$ days & & & & & & & 0.622 \\
\hline Yes & 34 & 61.8 & 14 & 56.0 & 48 & 60.0 & \\
\hline No & 21 & 38.2 & 11 & 44.0 & 32 & 40.0 & \\
\hline Oxygen therapy & & & & & & & 0.922 \\
\hline Using a Venturi mask & 8 & 14.5 & 6 & 24.0 & 14 & 17.5 & \\
\hline VMA & 9 & 16.4 & 2 & 8.0 & 11 & 13.7 & \\
\hline No & 38 & 69.1 & 17 & 68.0 & 51 & 68.8 & \\
\hline \multicolumn{8}{|l|}{ Time of $\mathrm{O}_{2}$ use } \\
\hline Median & \multicolumn{2}{|c|}{5 days } & \multicolumn{2}{|c|}{3 days } & \multicolumn{2}{|c|}{-} & \\
\hline Min-Max & \multicolumn{2}{|c|}{$(1-79)$} & \multicolumn{2}{|c|}{$(3-14)$} & \multicolumn{2}{|c|}{-} & \\
\hline Initial treatment & & & & & & & 0.539 \\
\hline Penicillin & 2 & 3.6 & 2 & 8.0 & 4 & 5.7 & \\
\hline Oxacilina-Ceftriaxone & 43 & 78.2 & 23 & 92.0 & 66 & 94.3 & \\
\hline Therapeutic failure & & & & & & & 0.070 \\
\hline Yes & 17 & 30.9 & 3 & 12.0 & 20 & 25.0 & \multirow[b]{3}{*}{ continue } \\
\hline \multirow[t]{2}{*}{ No } & 38 & 69.1 & 22 & 88.0 & 60 & 75.0 & \\
\hline & & & & & & & \\
\hline
\end{tabular}

$\mathrm{PNM}=$ Pneumonia; $\mathrm{PNMDP}=$ Pneumonia with pleural effusion; $\mathrm{ICU}=$ Intensive Care Unit; $\mathrm{VMA}=$ assisted mechanical ventilation; $\mathrm{O}_{2}=\mathrm{oxygen}_{\text {. }}$ 
Location and days of hospitalization, procedures and treatments and children complications with pneumonia hospitalized at Hospital da Restauração in Pernambuco, from May 2010 to May 2011, according to the presence of pleural effusion.

\begin{tabular}{|c|c|c|c|c|c|c|c|}
\hline \multirow[t]{2}{*}{ Variáveis } & \multicolumn{2}{|c|}{$\begin{array}{l}\text { PNM } \backslash \text { DP(Grupo I) } \\
\qquad(\mathrm{N}=55)\end{array}$} & \multicolumn{2}{|c|}{$\begin{array}{c}\text { PNM (Grupo II) } \\
(\mathrm{N}=25)\end{array}$} & \multicolumn{2}{|c|}{ Total } & \multirow[t]{2}{*}{$p$} \\
\hline & $\mathrm{n}$ & $\%$ & $\mathrm{n}$ & $\%$ & $\mathrm{n}$ & $\%$ & \\
\hline Other complication & & & & & & & 0.486 \\
\hline Pneumothorax & 0 & - & 2 & 8.0 & 2 & 2.5 & \\
\hline Emphysema & 13 & 23.6 & 0 & - & 13 & 16.5 & \\
\hline Empyema & 2 & 3.6 & 3 & 12.0 & 5 & 6.2 & \\
\hline No & 40 & 72.7 & 20 & 80.0 & 60 & 75.0 & \\
\hline Thoracentesis & & & & & & & $<0.001$ \\
\hline Yes & 55 & 100.0 & 3 & 12.0 & 58 & 72.5 & \\
\hline No & 0 & - & 22 & 88.0 & 22 & 27.5 & \\
\hline
\end{tabular}

$\mathrm{PNM}=$ Pneumonia; $\mathrm{PNMDP}=$ Pneumonia with pleural effusion; $\mathrm{ICU}=$ Intensive Care Unit; VMA= assisted mechanical ventilation; $\mathrm{O}_{2}=\mathrm{oxyg}_{\mathrm{g}}$.

Table 3

Outcome of the cases according to the location of origin and time of hospitalization. Hospital da Restauração, May 2010 and May 2011.

\begin{tabular}{|c|c|c|c|c|c|c|}
\hline \multirow{3}{*}{ Origin } & \multicolumn{4}{|c|}{ Outcome } & \multirow{3}{*}{ Total } & \multirow{3}{*}{$p$} \\
\hline & \multicolumn{2}{|c|}{ Death } & \multicolumn{2}{|c|}{ Hospital leave by cure } & & \\
\hline & $\mathrm{n}$ & $\%$ & $\mathrm{n}$ & $\%$ & & \\
\hline Countryside of the State & 6 & 100.0 & 34 & 46.7 & 40 & 0.026 \\
\hline Metropolitan Region & 0 & - & 40 & 53.3 & 40 & \\
\hline Hospitalization duration (days) & & & & & & $<0.001$ \\
\hline$<4$ & 3 & 50.0 & 0 & - & - & \\
\hline$>4$ & 3 & 50.0 & 74 & 100.0 & - & \\
\hline
\end{tabular}

approximately $50 \%$ in the medical files. Particularly, the lack of registration on $\mathrm{O}_{2}$ saturation draws attention, because the hypoxia is an important severe predictor and lethality for children with pneumonia, and serves to define the best practice for these patients, as the early use of oxygen, which reduces the hypoxia tissue and improves the located immunological response. 19,20

Lozano, 20 in a systematic review, observed the risk of death in children with pneumonia and $\mathrm{O}_{2}$ saturation lower than $92 \%$ may vary from 1.4 to 4.6 , demonstrating the relevance of this parameter. The presence of SCS was the only severe predictor, however, the veracity of this observation should be seen with parsimony due to the loss of the registration of half of the medical files of both groups.

The request for blood culture of patients with pneumonia at admission is unusual and, of 80 patients, 24 were requested, however, there are no registration of the results in the medical files, but a insignificant attention was given to this exam and it seems to be repeating in other regions of the country. 21 Although a low sensitivity exam,2,21 should be routinely performed in hospitalized patients with pneumonia,2,21 especially those of greater severity, once the initial treatment is empirical and the positive blood culture result could direct to a better therapy, in addition to provide information on the hospital biome.

The occurrence of pleural effusion in pneumonia is $2 \%$ to $30 \%$, and is associated with a higher risk of death. $7,22.23$ In this study, pneumonia associated with pleural effusion occurred more frequently in children younger than five years old, and has been 
associated to higher therapeutic failure and thoracentesis. The finding of $69 \%$ of patients' medical files in group I had registered a cloudy drained pleural fluid and in only nine cases were requested a culture and beyond the results were duly noted, there were doubts about the existence of the protocol to perform a culture of these cases along with the follow-up. Also, it was questioned the non- valued registry or the limitation of resources to perform the exam, which may be contributing to the therapeutic failure and the selection of bacteria resistant to antibiotics of frequent use in the hospital environment.2,24,25

Malnutrition and anemia observed in children do not interfere in the severity of pneumonia, although these are diseases jeopardizing the immune response and indirectly the response of the treatment.7,26-28 On the other hand, the immaturity of the immune system, especially with younger children, may have contributed to the unfavorable outcome of six children.

Most of the deaths from pneumonia in pediatrics occur in developing countries, $1,2,4,28$ where the access to healthcare is precarious and the health services often do not have the minimum resources to appropriately attend these children, such as the support for oxygen therapy, proper medication and qualified physician to monitor these children.28 Although it is not possible to establish the causeeffect relationship between the exclusive occurrence of deaths in smaller children who were admitted to HR, transferred to other health units, especially from the countryside in the state of Pernambuco, where there is little availability of physicians that could identify the patients' clinical signs of great severity in advance, associated to a deficient structure, questioning the role this factor may have contributed to these deaths, knowing that $50 \%$ of the six patients presented a fatal outcome with less than four days of admission.

An advance attendance for a child suspicious of having pneumonia and the proper classification of severity is fundamental, knowing that the increased proportion of children with severe pneumonia are those of younger age, suggesting the immaturity of the children's immune system may be a severe factor to the clinical framework and to the response of the treatment, being intensified by the delay in initiating the treatment. The scenario becomes more complex when the microbiological confirmation of the infection is negative, beginning a treatment with antibiotics in a presumptive manner in relation to the etiological agent and the sensitivity to the choice of the antibiotic.

The risk factor interferences in developing countries have contributed greatly to reduce pneumonia, diarrhea and measles mortality which together were responsible for 3.6 million deaths registered in 2013 in comparison to 2000. Studies show that actions on the modifiable risk factors will lead to a progressive reduction of mortality due to this cause. ${ }^{3}$

Finally, the clinical signals required to classify the severity of the disease are easily obtained with physical examination and should be registered for all the patients presenting pneumonia symptoms at the attendance in any health unit, mainly at high complexity care units and school hospital. In Figure 2 shows a flowchart of hospital attendance of children with pneumonia which could assist the physician to define the protocol for the children's treatment for the severe disease, however, it is necessary to emphasize the importance to register the fundamental instrument for health manager's decisionmaking, but also to scientific research and health professional training.

The elaboration of a score, the example that already has been proposed to identify in advance children with suggestive signs of severe pneumonia is an important tool for professionals to perform the first medical care, either in the family health programs, hospitals located in the countryside of the State and tertiary care hospitals, allowing the standardization of protocols care define where the patient will be treated and the best support for the case contributing in reducing death risks of pneumonia.

\section{Acknowledgements}

The authors would like to thank the State Secretary of Health and the hospital staff at Hospital da Restauração for the administrative and technical support to implement this study. 


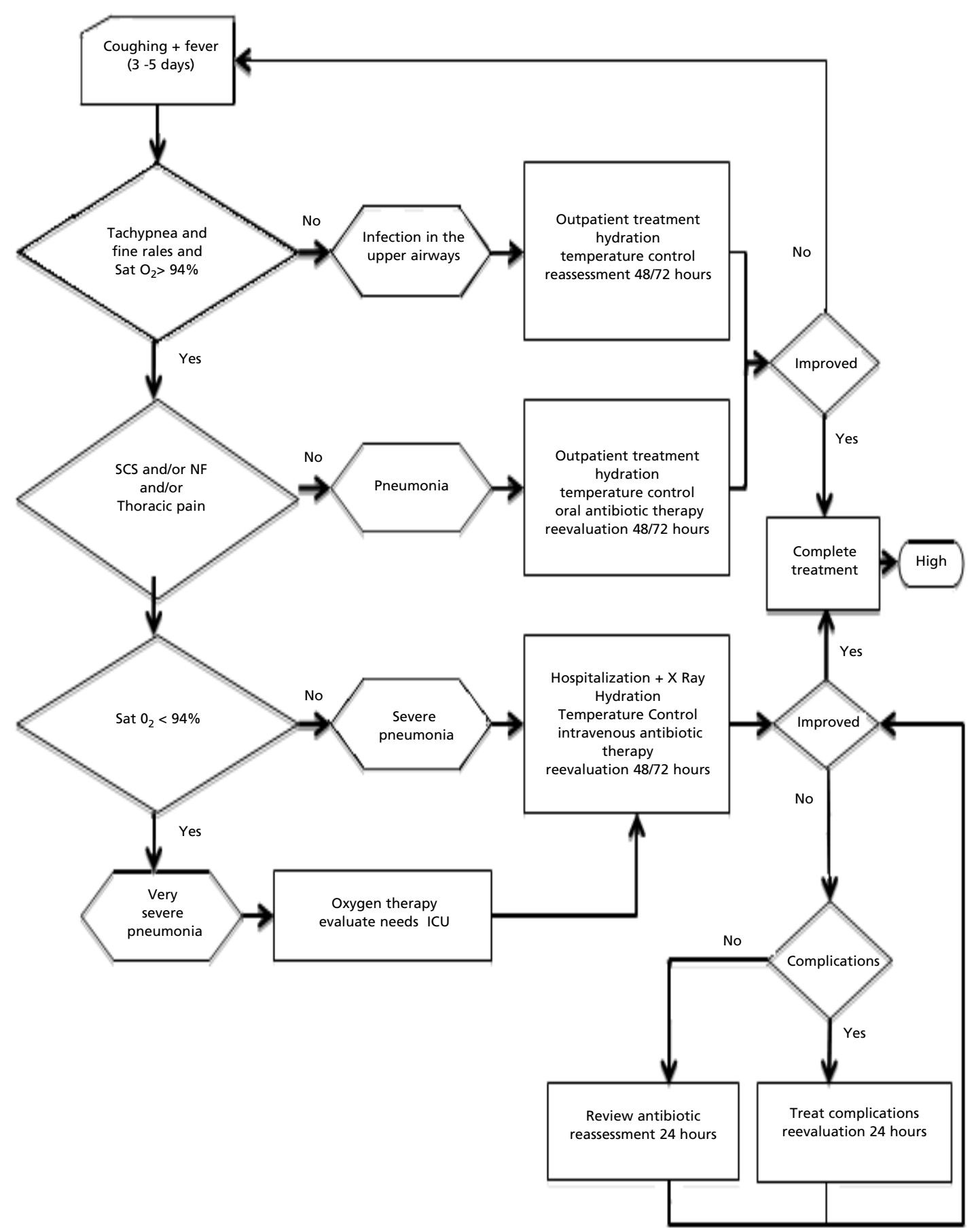

$\mathrm{NF}=$ Nostril flaring; $\mathrm{SCS}=$ Subcostal screening 


\section{References}

1. Izadnegahdar $\mathrm{R}$, Cohen $\mathrm{AL}$, Klugman KP, Qazi SA Childhood pneumonia in developing countries. Lancet Respir. 2013; 1 (7): 574-84.

2. Diretrizes Brasileiras em Pneumonia Adquirida na Comunidade em Pediatria. J Bras Pneumol. 2007; 33(Supl. 1): S31-S50.

3. Rudan I, O'Brien KL, Nair H, Liu L, Theodoratou E, Qazi $\mathrm{S}$, et al, Child Health Epidemiology Reference Group (CHERG) Epidemiology and etiology of childhood pneumonia in 2010: estimates of incidence, severe morbidity, mortality, underlying risk factors and causative pathogens for 192 countries. J Glob Health. 2013; 3 (1): 010401.

4. Nair H, Simões E a F, Rudan I, Gessner BD, AzzizBaumgartner E, Zhang JS, Feikin DR, Mackenzie GA, Moïsi JC, Roca A, Baggett HC,Zaman SM, Singleton RJ, Lucero MG, Chandran A, Gentile A, Cohen C, Krishnan A, Bhutta ZA, Arguedas A, Clara AW, Andrade AL,Ope M, Ruvinsky RO, Hortal M, McCracken JP, Madhi SA, Bruce N, Qazi SA, Morris SS, El Arifeen S, Weber MW, Scott JA, Brooks WA,Breiman RF, Campbell H; Severe Acute Lower Respiratory Infections Working Group. Global and regional burden of hospital admissions for severe acute lower respiratory infections in young children in 2010: a systematic analysis. Lancet. 2013; 381 (9875): 1380-90.

5. Li Liu, Shefali Oza, Daniel Hogan, Jamie Perin, Igor Rudan, Joy E Lawn, Simon Cousens, Colin Mathers, Rober E Black, Global, regional, and national causes of child mortality in 2000-13, with projections to inform post-2015 priorities: an updated systematic analysis, Lancet. 2015; 385: 430-40.

6. Brasil. DATASUS.gov.br. Tab Net Win32 2_4C7. Sistema de informações sobre nascidos vivos-SINASC, Sistema de informações sobre mortalidade-SIM, IBGE- estimativas demográficas. Acesso em maio 2014. 2014:2014

7. Wonodi CB, Deloria-Knoll M, Feikin DR, DeLuca AN Driscoll AJ, Moïsi JC, Johnson HL, Murdoch DR, O'Brien KL, Levine OS, Scott JA; Pneumonia Methods Working Group and PERCH Site Investigators. Evaluation of risk factors for severe pneumonia in children: the Pneumonia Etiology Research for Child Health study. Clin Infect Dis. 2012; 54 (Suppl. 2): S124-31.

8. Loke YK, Kwok CS, Niruban A, Myint PK. Value of severity scales in predicting mortality from communityacquired pneumonia: systematic review and meta-analysis. Thorax. 2010; 65 (10): 884-90.

9. Jackson S, Mathews KH, Pulanić D, Falconer R, Rudan I, Campbell H, Nair H. Risk factors for severe acute lower respiratory infections in children - a systematic review and meta-analysis. Croat Med J. 2013; 54 (2): 110-21.

10. Solé-Violán J, de Castro F V, García-Laorden MI, Blanquer J, Aspa J, Borderías L, Briones ML, Rajas O, Carrondo IM, Marcos-Ramos JA, Ferrer Agüero JM, Garcia-Saavedra A, Fiuza MD, Caballero-Hidalgo A, Rodriguez-Gallego C. Genetic variability in the severity and outcome of community-acquired pneumonia. Respir Med. 2010; 104 (3): 4407 .

11. Moore PC, Huang C, Rodriguez A, Wiebe R, Siegel J. Presenting Signs and Symptoms of Rapidly Progressing Severe Pneumonia in the Pediatric Emergency Department. Emergency Med. 2013; 3: 2.
12. Moustaki M, Zeis PM, Katsikari M, Fretzayas A, Grafakou O, Stabouli S, Tsolia M, Nicolaidou P, Karpathios T. Mesenteric lymphadenopathy as a cause of abdominal pain in children with lobar or segmental pneumonia. Pediatr Pulmonol. 2003; 35 (4): 269-73.

13. Tsalkidis A, Gardikis S, Cassimos D, Kambouri K, Tsalkidou E, Deftereos S, Chatzimichael A. Acute abdomen in children due to extra-abdominal causes. Pediatr Int. 2008; 50: 315-8.

14. Ku C-L, von Bernuth H, Picard C, Zhang SY, Chang HH, Yang K, Chrabieh M, Issekutz AC, Cunningham CK, Gallin J, Holland SM,Roifman C, Ehl S, Smart J, Tang M, Barrat FJ, Levy O, McDonald D, Day-Good NK, Miller R, Takada H, Hara T, Al-Hajjar S, Al-Ghonaium A, Speert D, Sanlaville D, Li X, Geissmann F, Vivier E, Maródi L, Garty BZ, Chapel H, Rodriguez-Gallego C, Bossuyt X, Abel L, Puel A, Casanova JL. Selective predisposition to bacterial infections in IRAK-4-deficient children: IRAK-4-dependent TLRs are otherwise redundant in protective immunity. J Exp Med. 2007; 204 (10): 2407-22.

15. Calbo E, Díaz a, Cañadell E, Fábrega J, Uriz S, Xercavins M, Morera MA, Cuchi E, Rodríguez-Carballeira M, Garau J; Spanish Pneumococcal Infection Study Network. Invasive pneumococcal disease among children in a health district of Barcelona: early impact of pneumococcal conjugate vaccine. Clin Microbiol Infect. 2006; 12 (9): 867-72.

16. Castro AV, Nascimento-Carvalho CM, Ney-Oliveira F, Araújo-Neto CA, Andrade SCS, Loureiro LLS, Luz PO. Additional markers to refine the World Health Organization algorithm for diagnosis of pneumonia. Indian Pediatr. 2005; 42: $773-81$

17. Domecq JP, Prutsky G, Lazo MA, Salazar C, Montori V, Prevost Y, Huicho L, Erwin P Málaga G. Precisión de la taquipnea y las retracciones subcostales como signos clínicos para diagnóstico de neumonía adquirida en la comunidad en niños: revisión sistemática y metaanálisis. Rev Peru Med Exp Salud Publica. 2012; 29 (3): 337-44.

18. Mahabee-Gittens EM. Identifying Children with Pneumonia in the Emergency Department. Clin Pediatr (Phila). 2005; 44 (5): 427-35.

19. Delclaux C, Azoulay E. Inflammatory response to infectious pulmonary injury. Eur Respir J. 2003; 22 (Suppl. 42): $10 \mathrm{~s}-14 \mathrm{~s}$.

20. Lozano JM. Epidemiology of hypoxaemia in children with acute lower respiratory infection. Int J Tuberc Lung Dis. 2001; 5 (6): 496-504.

21. Veras T N, Sandim G, Mundim K, Petrauskas R, Cardoso G, D'Agostin J. Epidemiological profile of pediatric in patients with pneumonia. Sci Med. 2010; 20 (4): 277-81.

22. Chisti MJ, Tebruegge M, La Vincente S, Graham SM, Duke T. Pneumonia in severely malnourished children in developing countries - mortality risk, aetiology and validity of WHO clinical signs: a systematic review. Trop Med Int Health. 2009; 14 (10): 1173-89.

23. Martín AA, Moreno-Pérez D, Miguélez SA, Gianzo JAC, García MLG, Murua JK, León MIM, Almagro CM, Santaella IO, Pérez GP. Etiología y diagnóstico de la neumonía adquirida en la comunidad y sus formas complicadas. An Pediatr (Barc). 2012; 76 (3): 162.e1-162.e18. 
24. Pinto KDBPC, Maggi RRS, Alves JGB. Análise de risco socio-ambiental para comprometimento pleural na pneumonia grave em crianças menores de 5 anos. Rev Panam Salud Publica. 2004; 15 (2): 104-9.

25. Muhammad MIA. Management of complicated parapneumonic effusion and empyema using different treatment modalities. Asian Cardiovasc Thorac Ann. 2012; 20 (2) $177-81$.

26. Chisti MJ, Salam MA, Ashraf H, Faruque AS, Bardhan PK, Hossain MI, Shahid AS, Shahunja KM, Das SK, Imran G Ahmed T. Clinical risk factors of death from pneumonia in children with severe acute malnutrition in an urban critical care ward of Bangladesh. PLoS One. 2013; 8 (9): e73728.
27. Ekiz C, Agaoglu L, Karakas Z, Gurel N, Yalcin I. The effect of iron deficiency anemia on the function of the immune system. Hematol J.2005; 5 (7): 579-83.

28. Harris AH, Sempértegui F, Estrella B, Narváez X, Egas J, Woodin M, Durant JL, Naumova EN, Griffiths JK. Air pollution and anemia as risk factors for pneumonia in Ecuadorian children: a retrospective cohort analysis. Environmental Health. 2011; 10: 93.

29. Myint PK, Sankaran P, Musonda P, Subramanian DN, Ruffell H, Smith AC, Prentice P, Tariq SM,Kamath AV. Performance of CURB-65 and CURB-age in communityacquired pneumonia. Int J Clin Pract. 2009; 63 (9): 1345 50

Received on January 14, 2015

Final version presented on February 2, 2016

Approved on March 31, 2016 